\title{
Note on Language Use and Transliteration
}

Throughout this book I have used Hausa orthography rather than English or Arabic in the spelling of personal names, place names, and substantive vocabulary words. In those cases where a Hausa word is based on an Arabic root, I have included the Arabic word in parentheses the first time the Hausa word is used. Where such exist, I have preferred an anglicized form over Hausa or Arabic spellings, as with tariqa, imam, etc. In cases where North African or Arab names are mentioned I have transliterated from the Arabic, but have followed Hausa orthography for all persons, including Arabs, who have lived in Kano or are associated with Kano history. I have included in the glossary a list of Hausa words and names used in the text, with their Arabic and English equivalents.

With regard to transliteration, there are no diacritical marks other than the apostrophe in Hausa, but there are certain glottalized consonants which are expressed orthographically as hooked letters, namely, b, d, and $k$. I have not used hooked letters in this text because there is little possibility that a Hausa word would be misconstrued. With regard to Arabic transliteration I have used the standard forms (as outlined in Cataloging Service, Library of Congress, “Arabic Romanization," Bulletin 9I, September 1970) except on certain matters of capitalization (where I have used anglicized style) and ordering of segments of proper names (where I have not used nisbahs initially but rather have listed authors alphabetically by first name). 
